\title{
Involvement of TWEAK and the NF-кB signaling pathway in lupus nephritis
}

\author{
FANG SUN ${ }^{1 *}$, JIAN TENG $^{1 *}$, PENGFEI YU ${ }^{2}$, WENSHUANG $\mathrm{LI}^{3}$, JING CHANG $^{1}$ and HONGLEI XU ${ }^{1}$ \\ ${ }^{1}$ Department of Nephrology, Yantaishan Hospital; ${ }^{2}$ Department of Respiratory Medicine, \\ Yantai Yuhuangding Hospital, Yantai, Shandong 264000; ${ }^{3}$ Department of Internal Medicine, \\ Laiyang Tuberculosis Prevention Institution, Laiyang, Shandong 265299, P.R. China
}

Received October 27, 2016; Accepted August 28, 2017

DOI: $10.3892 /$ etm.2018.5711

\begin{abstract}
Previous findings have identified that tumor necrosis factor-related weak inducer of apoptosis (TWEAK) is associated with lupus nephritis (LN) activity status; however, the mechanism involved remains unclear. The present study aimed to investigate the roles of TWEAK and the nuclear factor $(\mathrm{NF})-\kappa \mathrm{B}$ signaling pathway in LN. TWEAK levels in the blood and urine of patients with LN or non-LN systemic lupus erythematosus were measured by ELISA and compared with those in healthy controls. TWEAK expression and $\mathrm{NF}-\kappa \mathrm{B}$ transcriptional activity in the kidney were detected by western blotting, and Ki-67 and cluster of differentiation (CD) 68 expression were assessed using immunofluorescence. Additionally, human mesangial cells (HMCs) were cultured in vitro and divided into five groups: Normal control, TWEAK stimulus group, TWEAK + TWEAK blocking antibody, TWEAK + NF- $\mathrm{B}$ inhibitor (BAY 11-7082) and TWEAK + combined (blocking antibody + BAY 11-7082). Cell cycle activity and Ki-67 expression in the HMCs were evaluated using flow cytometry, and cell induction of macrophage chemotaxis was determined by a Transwell assay. Levels of the inflammation-associated factors interleukin (IL)-6, monocyte chemotactic protein 1 (MCP-1), chemokine ligand 5 (CCL5), IL-8 and IL-10 were also detected by reverse transcription-quantitative polymerase chain reaction. It was observed that the urine levels of TWEAK in patients with LN were significantly elevated compared with those in the other groups $(\mathrm{P}<0.05)$. LN kidneys exhibited markedly increased cell proliferative ability, macrophage infiltration, TWEAK
\end{abstract}

Correspondence to: Dr Pengfei Yu, Department of Respiratory Medicine, Yantai Yuhuangding Hospital, 20 Yuhuangding East Road, Yantai, Shandong 264000, P.R. China

E-mail: yupengfeikk@163.com

${ }^{*}$ Contributed equally

Key words: lupus nephritis, tumor necrosis factor-related weak inducer of apoptosis, nuclear factor- $\mathrm{kB}$, human glomerular mesangial cells, cell proliferation, chemotaxis expression and $\mathrm{NF}-\kappa \mathrm{B}$ transcriptional activity compared with normal kidneys. Furthermore, the results indicated that treatment with recombinant TWEAK notably enhanced $\mathrm{NF}_{-} \kappa \mathrm{B}$ transcriptional activity and significantly promoted cell proliferation and cell cycle activity $(\mathrm{P}<0.05)$, induced macrophage chemotaxis $(\mathrm{P}<0.05)$, significantly increased the expression of the chemotactic factors IL-6, IL-8, MCP-1 and CCL5 $(\mathrm{P}<0.05)$, and significantly reduced anti-inflammatory cytokine IL-10 mRNA expression in HMCs $(\mathrm{P}<0.05)$, relative to normal controls. Accordingly, blocking TWEAK function or inhibiting NF- $\kappa \mathrm{B}$ activity reversed these effects. Collectively these data indicate that urine TWEAK may be considered as a novel biomarker of LN activity, and that blocking TWEAK function or $\mathrm{NF}-\kappa \mathrm{B}$ activity may effectively alleviate glomerular mesangial cell proliferation and macrophage chemotaxis.

\section{Introduction}

Systemic lupus erythematosus (SLE) is a type of autoimmune disease characterized by multisystem damage combined with the formation of a variety of autoantibodies, though has unknown etiology $(1,2)$. The kidneys are the primary affected organ, and once affected, the condition is classified as lupus nephritis (LN) (3). LN is an important feature of SLE in the clinic, as $\sim 30-50 \%$ of patients with SLE present with renal damage (4). The clinical manifestations of renal damage include proteinuria, erythrocyturia, leucocyturia, cylindruria, glomerular filtration dysfunction and renal tubular hypofunction (5). The manifestation of LN typically alternates between active and inactive stages. Additionally, the severity of renal damage has been associated with the prognosis of SLE (6). A progressive decrease in renal function in active stage LN is among the leading causes of mortality in SLE patients (7). Renal puncture biopsy is considered the gold standard for LN diagnosis, assessment of LN activity status and determination of renal damage severity (8). However, renal puncture biopsies are invasive with poor reproducibility.

Identification of LN activity-related clinical indicators is of importance for improving diagnosis and treatment. Previous studies have investigated novel potential biomarkers for the assessment of LN activity $(8,9)$. In addition, a variety of studies have demonstrated the value of TWEAK in assessing renal damage severity (10-12). Notably, it has been reported that 
urine TWEAK content in patients with active LN was significantly higher than in those with inactive LN (13), and that urine TWEAK level was correlated with the degree of renal damage (14). Previous results also indicated that TWEAK was highly expressed in the renal tissue of an LN animal model (15). Furthermore, blockade of TWEAK expression or knockout of its cognate receptor fibroblast growth factor inducer 14 (Fn14) in LN mice relieved renal tissue damage and alleviated inflammatory cell infiltration, inflammatory cytokine production and immunoglobulin deposition (16).

Nuclear factor (NF) $-\mathrm{kB}$ is a transcription factor that forms a p65-p50 heterodimer in the cytoplasm and participates in the immune inflammatory response, cell differentiation, cell growth and apoptosis regulation (17). TWEAK may activate the $\mathrm{NF}-\kappa \mathrm{B}$ signaling pathway through binding with the Fn14 receptor, which may represent an underlying mechanism regarding LN activity status (18). A previous study has indicated that TWEAK is associated with LN activity (19); however, the specific mechanism involved remains unclear. Thus, the present study aimed to investigate the roles of TWEAK and the NF- $\mathrm{NB}$ signaling pathway in $\mathrm{LN}$.

\section{Materials and methods}

Case collection. A total of 65 patients with SLE with LN (6 males and 59 females; age, 36.7 \pm 14.5 years old) were enrolled from Yantaishan Hospital (Yantai, China) between January 2014 and August 2015. The diagnosis of SLE was determined according to the 1999 SLE classification standards revised by the American rheumatism association (20). The following LN diagnostic criteria were used: Patients with SLE presenting with persistent proteinuria (24-h urine protein, $>0.5 \mathrm{~g}$ ), erythrocyturia, leucocyturia, cylindruria and confirmation by renal biopsy. A total of 45 patients with SLE without LN (5 males and 40 females; age, 37.2 \pm 15.1 years old) were enrolled as a non-LN SLE group over the same time period. Patients with malignant tumors, acute or chronic infection, or other autoimmune diseases were excluded. All the enrolled patients had received no immunosuppressant therapy (including cyclophosphamide, methyl prednisone and cyclosporine A), immunomodulators or hormone therapy. Additionally, 50

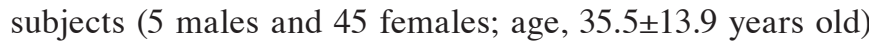
receiving physical health examinations were enrolled as the normal controls. The subjects in the normal control group did not suffer from diabetes or hypertension, had a normal biochemical index (serum creatine kinase, triglycerides, C3/4, C-reactive protein and high density lipoprotein) and tested negative for autoantibodies. No statistically significant differences in age or gender were observed among the groups (Table I). In addition, another 30 patients with renal tumors (3 males and 27 females; age, 36.2 \pm 12.1 ) were also recruited between January 2014 and August 2015 (Table I), these patients had no primary glomerular nephritis or other diseases that may affected renal function, such as diabetes or hypertension.

The study protocol was approved by the Research Ethics Committee of Yantaishan Hospital and all patients provided their informed written consent prior to study commencement.

Reagents and materials. Recombinant human TWEAK cytokine (cat. no. 1090-TW-025) and goat anti-human
TWEAK antibody (cat. no. AF1199-SP) were purchased from R\&D Systems, Inc. (Minneapolis, MN, USA). NF- $\kappa$ B p65 (cat. no. sc-372), NF-кB p65 [phospho (p)-S536; p-p65; cat. no. sc-136548] and $\beta$-actin antibodies (cat. no. sc-47778) were purchased from Santa Cruz Biotechnology, Inc. (Dallas, TX, USA). p-NF- $\kappa$ light polypeptide gene enhancer in B-cells inhibitor- $\alpha(\mathrm{I} \kappa \mathrm{B} \alpha$; p-S32; cat. no. 9246) and histone H3.1 antibodies (cat. no. 9715) were purchased from Cell Signaling Technology, Inc. (Danvers, MA, USA). Rabbit antihuman cluster of differentiation (CD)68 (cat. no. ab125212) and Ki-67 antibodies (cat. no. ab92742) were obtained from Abcam (Cambridge, MA, USA). The allophycocyanin (APC)-tagged mouse antihuman Ki-67 antibody (cat. no. 17-5699-42) for flow cytometry and TWEAK ELISA kit (cat. no. 15215014) were purchased from eBioscience; Thermo Fisher Scientific, Inc. (Waltham, MA, USA). A Total Protein Extraction kit was purchased from in Phygene Life Sciences Co., Ltd. (Fuzhou, China). The NF- $\kappa$ B inhibitor BAY 11-7082, cytoplasm and nucleoprotein separation kits were obtained from Beyotime Institute of Biotechnology (Haimen, China). Human normal mesangial cells (cat. no. T4086) were purchased from Applied Biological Materials Inc. (Richmond, BC, Canada).

Sample collection and indicator detection. Blood $(5 \mathrm{ml})$ and urine $(3 \mathrm{ml})$ specimens were collected from all subjects. Blood samples were clotted and centrifuged at 1,500 $\mathrm{x} g$ for $10 \mathrm{~min}$ at room temperature to separate the upper serum. The contents of TWEAK in the blood and urine were determined by ELISA according to the manufacturer's protocol. SLE disease activity index (SLEDAI) in SLE patients with or without LN was evaluated according to clinical manifestation and laboratory examination as previously described (21). SLEDAI scores $\leq 4$ were considered to represent inactive stage LN, whereas SLEDAI scores $\geq 5$ were considered to represent active LN (22). Among the total 65 patients with $\mathrm{LN}, 40$ cases were assigned to the non-active LN group) and 25 cases were assigned to the active LN group (Table II). No significant age or gender differences were identified between these groups. Renal tissue pathological samples from patients with LN were collected during a biopsy. Other renal tissues from age- and gender-matched renal tumor patients were selected as controls. The samples were collected from a site at least $3 \mathrm{~cm}$ from the tumor and confirmed to be normal renal tissue by pathology. The collected samples were used for frozen sectioning $\left(5-\mu \mathrm{m}\right.$-thick) at $-80^{\circ} \mathrm{C}$ and renal cortex protein extraction.

Western blotting. Total protein and nucleoprotein were extracted using a Total Protein Extraction, and Nuclear and Cytoplasmic Protein Extraction kits, respectively, according to the manufacturer's protocol. Proteins were quantified using a BCA assay kit and $20 \mu \mathrm{g}$ of protein was loaded per lane were loaded and separated by $12 \%$ SDS-PAGE. Proteins were subsequently transferred to polyvinylidene difluoride membranes and the membranes were blocked using 5\% skimmed milk at room temperature for $1 \mathrm{~h}$. The membranes were subsequently incubated with primary antibodies directed against TWEAK (1:1,000), p-p65 (1:500), p-IкB $\alpha$ $(1: 1,000)$ and $\beta$-actin $(1: 1,000)$ at $4^{\circ} \mathrm{C}$ overnight, and then HRP-conjugated goat-anti rabbit (cat. no. 65-6120; 1:5,000) 
Table I. Characteristics of patients and controls.

\begin{tabular}{|c|c|c|c|c|}
\hline Characteristic & SLE with LN & SLE without LN & Normal controls & Renal tumor patients \\
\hline Group size & 65 & 45 & 50 & 30 \\
\hline Male/female & $6 / 59$ & $5 / 40$ & $5 / 45$ & $3 / 27$ \\
\hline Age $($ mean $\pm \mathrm{SD})$ & $36.7 \pm 14.5$ & $37.2 \pm 15.1$ & $35.5 \pm 13.9$ & $36.2 \pm 12.1$ \\
\hline
\end{tabular}

LN, lupus nephritis; SLE, systemic lupus erythematosus; SD, standard deviation.

or rabbit anti-mouse (cat. no. 61-6520; 1:5,000) (both Thermo Fisher Scientific, Inc.) secondary antibodies at room temperature for $1 \mathrm{~h}$. Following enhanced chemiluminescence development using the Pierce ${ }^{\mathrm{TM}}$ ECL Western Blotting Substrate (cat. no. 32106; Thermo Fisher Scientific, Inc.), the $\mathrm{X}$-ray film was scanned to detect the expression of TWEAK, $\mathrm{p}$-p65, $\mathrm{p}-\mathrm{I}_{\kappa} \mathrm{B} \alpha$ and $\beta$-actin in the renal cortex.

Immunofluorescence. The frozen sections were dried at room temperature for $15 \mathrm{~min}$ and washed three times with PBS to remove optimal cutting temperature compound. Subsequently, the sections were blocked in PBS containing 10\% goat serum (cat. no. 16210064; Thermo Fisher Scientific, Inc.) at room temperature for $60 \mathrm{~min}$ and incubated with the rabbit anti-human CD68 $(1 \mu \mathrm{g} / \mathrm{ml})$ and $\mathrm{Ki}-67(1 \mu \mathrm{g} / \mathrm{ml})$ antibodies at $4^{\circ} \mathrm{C}$ overnight. After washing, the sections were incubated with IgG Alexa Fluor 594 (cat. no. R37117) and Alexa Fluor 488 (cat. no. R37116) fluorescence secondary antibodies (both $2 \mu \mathrm{g} / \mathrm{ml}$; Thermo Fisher Scientific, Inc.) at room temperature for $1 \mathrm{~h}$. Following staining with 4',6-diamidino-2-phenylindole at room temperature for $1 \mathrm{~h}$, the sections were sealed and observed under a fluorescence microscope (magnification, $\mathrm{x} 40$ ).

Cell culture and grouping. HMCs were routinely cultured in RPMI-1640 medium supplemented with 10\% FBS, $10 \mathrm{mg} / \mathrm{l}$ insulin, $5.5 \mathrm{mg} / 1$ transferrin, and $6.7 \mu \mathrm{g} / 1$ sodium selenite (all Thermo Fisher Scientific, Inc.) at $37^{\circ} \mathrm{C}$ with $5 \% \mathrm{CO}_{2}$. The cells were divided into five groups: Normal control without any treatment; stimulus group (50 ng/ml recombinant TWEAK); neutralizing antibody group [50 ng/ml TWEAK + $200 \mathrm{ng} / \mathrm{ml}$ anti-TWEAK antibody (blocking antibody)]; NF- $\kappa \mathrm{B}$ inhibitor group (50 ng/ml TWEAK + $2 \mu \mathrm{g} / \mathrm{ml} \mathrm{BAY} \mathrm{11-7082);} \mathrm{and}$ combined inhibition group (50 ng/ml TWEAK + $200 \mathrm{ng} / \mathrm{ml}$ blocking antibody $+2 \mu \mathrm{g} / \mathrm{ml}$ BAY 11-7082). BAY 11-7082 was added 30 min prior to TWEAK treatment. The cells $\left(1 \times 10^{6} / \mathrm{ml}\right.$ seeding density) were collected following incubation with the various treatments (the anti-TWEAK blocking antibody was added 10 min prior to the administration of TWEAK) for $48 \mathrm{~h}$ at $37^{\circ} \mathrm{C}$ and used in subsequent assays. Western blot analysis was performed as above to detect p65 protein nuclear transport and $\mathrm{I}_{\kappa} \mathrm{B} \alpha$ phosphorylation in the HMCs with the primary

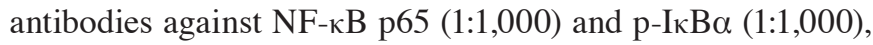
using histone H3.1 $(1: 1,000)$ and $\beta$-actin $(1: 1,000)$ as internal controls, respectively followed by the addition of secondary antibodies as described above. Additionally, the cells were subjected to reverse transcription quantitative-polymerase chain reaction (RT-qPCR) for further marker detection.
$R T$ - $q P C R$. Total RNA was extracted from cells using TRIzol (Thermo Fisher Scientific, Inc.) and reverse transcribed to complementary (c)DNA using random primers and oligdT primers from the High-Capacity cDNA Reverse Transcription kit (Thermo Fisher Scientific Inc.). cDNA was used as a template for PCR amplification. The primers used were as follows: Interleukin (IL)-8, forward, 5'-TTTTGCCAAGGA GTGCTAAAGA-3' and reverse, 5'-AACCCTCTGCACCCA GTTTTC-3'; IL-6, forward, 5'-ACTCACCTCTTCAGAACG AATTG-3' and reverse, 5'-CCATCTTTGGAAGGTTCAGGT TG-3'; chemokine ligand 5 (CCL5), forward 5'-CCAGCA GTCGTCTTTGTCAC-3' and reverse 5'-CTCTGGGTTGGC ACACACTT-3'; monocyte chemoattractant protein (MCP)-1, forward, 5'-CAGCCAGATGCAATCAATGCC-3' and reverse, 5'-TGGAATCCTGAACCCACTTCT-3'; IL-10, forward 5'-GACTTTAAGGGTTACCTGGGTTG-3' and reverse, 5'-TCACATGCGCCTTGATGTCTG-3'; and $\beta$-actin, forward 5'-GCACTCTTCCAGCCTTCC-3' and reverse, 5'-AGA AAGGGTGTAACGCAACTAAG-3'. The reaction system contained 4.5 $\mu \mathrm{l}$ 2X SYBR Green PCR Master mix (Thermo Fisher Scientific, Inc.), $0.5 \mu 15 \mu \mathrm{m} / 1$ primers, $1 \mu \mathrm{l} \mathrm{cDNA}$, and

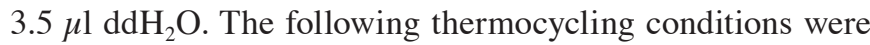
used: $95^{\circ} \mathrm{C}$ for $5 \mathrm{~min}$, followed by 40 cycles of $95^{\circ} \mathrm{C}$ for $15 \mathrm{sec}$ and $60^{\circ} \mathrm{C}$ for $1 \mathrm{~min}$. PCR was performed using an ABI ViiA7 PCR amplifier, and the products were quantified using the $2^{-\Delta \Delta \mathrm{Cq}}$ method (23) with $\beta$-actin as an internal reference. Each reaction was performed in triplicate.

Analysis of cell cycle progression and $\mathrm{Ki}-67$ expression by flow cytometry. Cells were digested using collagenase $(1 \mathrm{mg} / \mathrm{ml})$ and washed with PBS. Following fixation with $70 \%$ ethanol overnight at $4^{\circ} \mathrm{C}$, the cells were resuspended in $500 \mu \mathrm{l}$ PBS containing $50 \mu \mathrm{g} / \mathrm{ml}$ RNaseA at $37^{\circ} \mathrm{C}$ for $30 \mathrm{~min}$. Subsequently, the cells were treated with $0.1 \%$ Triton $\mathrm{X}-100$ for $30 \mathrm{~min}$ at room temperature, then stained with $50 \mu \mathrm{g} / \mathrm{ml}$ propidium iodide at $4^{\circ} \mathrm{C}$ for $30 \mathrm{~min}$ prior to cell cycle analysis using a Propidium Iodide Flow Cytometry kit for cell cycle analysis (cat. no. ab139418; Abcam). The data was analyzed using BD CellQuest Pro Software, version 5.1 (BD Biosciences, San Jose, CA, USA).

For measurement of Ki-67 expression, cells were digested by using collagenase $(1 \mu \mathrm{g} / \mathrm{ml})$ and washed with PBS. Subsequently, the cells were fixed with $4 \%$ paraformaldehyde at $4^{\circ} \mathrm{C}$ for $30 \mathrm{~min}$, and then with $0.1 \%$ saponin (Thermo Fisher Scientific, Inc.) for $20 \mathrm{~min}$ at room temperature. Following incubation with the APC-tagged Ki-67 antibody at $4^{\circ} \mathrm{C}$ for $60 \mathrm{~min}$ in the dark, the cells were analyzed by flow cytometry and data were analyzed by BD CellQuest Pro Software, version 5.1. 
Table II. Characteristics of SLE patients with LN.

\begin{tabular}{lcc}
\hline Characteristic & Non-actin LN & Active LN \\
\hline Group size (n) & 40 & 25 \\
Gender (m/f) & $4 / 36$ & $2 / 23$ \\
Age & $35.9 \pm 15.1$ & $37.1 \pm 14.8$ \\
\hline
\end{tabular}

LN, lupus nephritis.

Transwell assay. Collagen type IV was used to coat Transwell plates (pore size, $8 \mu \mathrm{m}$ ) and incubated for $24 \mathrm{~h}$ at $4^{\circ} \mathrm{C}$. THP- 1 macrophages obtained from the American Type Culture Collection were seeded $\left(1 \times 10^{6} / \mathrm{ml}\right)$ in the upper chamber containing RPMI-1640 medium, while HMCs from each of the five groups were seeded $\left(1 \times 10^{6} / \mathrm{ml}\right)$ in the lower chamber containing RPMI-1640 medium. Following $24 \mathrm{~h}$ incubation at $37^{\circ} \mathrm{C}$, the Transwell chamber was fixed with methanol for $30 \mathrm{~min}$ at room temperature and stained with $0.1 \%$ crystal violet for $20 \mathrm{~min}$ at room temperature. The cells were observed under a light microscope (magnification, $\mathrm{x} 400$ ) and counted under five random fields of vision.

Statistical analysis. SPSS 18.0 software (IBM Corp., Armonk, NY, USA) was used for data analysis. Data were presented as mean \pm standard deviation as indicated with a minimum of three independent experiments performed for each assay. A Student's t-test was performed for the comparison of differences between two groups. One-way analysis of variance with a Newman-Keuls multiple comparison post-hoc analysis was performed for significance comparisons among multiple treatment groups, while the $\chi^{2}$ test was used for enumeration data comparisons (patient gender and age). $\mathrm{P}<0.05$ was considered to indicate a statistically significant difference.

\section{Results}

TWEAK levels in different groups of patients and the association between TWEAK and LN activity. The ELISA results indicated that TWEAK levels in the urine of patients in the LN group were significantly increased compared with that in patients in the non-LN SLE and healthy control groups $(\mathrm{P}<0.05$; Table III). Meanwhile, the urine levels of TWEAK between non-LN SLE patients and healthy controls did not differ significantly $(\mathrm{P}>0.05)$. Serum TWEAK levels were similar and not significantly different among all three groups $(\mathrm{P}>0.05)$. Patients in the active LN group exhibited significantly increased urine levels of TWEAK compared with those in the LN inactive group $(\mathrm{P}<0.05)$, while the serum TWEAK levels did not differ significantly between the groups $(\mathrm{P}>0.05$; Table III).

TWEAK protein expression, inflammatory cell infiltration and cell proliferation in LN renal tissue. Western blotting demonstrated that, compared with the adjacent normal renal tissue of patients with renal tumors, the renal cortex of patients with LN exhibited markedly increased protein expression of TWEAK (Fig. 1A). Additionally, immunofluorescence
Table III. TWEAK content in different patient groups and the association between 19 TWEAK and LN activity.

\begin{tabular}{lccc}
\hline Grouping & $\mathrm{n}$ & Serum $(\mathrm{nmol} / \mathrm{l})$ & Urine $(\mathrm{nmol} / \mathrm{l})$ \\
\hline Patients groups & & & \\
$\quad$ Healthy control & 50 & $24.8 \pm 5.6$ & $9.4 \pm 3.1$ \\
Non-LN SLE & 45 & $23.4 \pm 6.2$ & $10.5 \pm 2.8$ \\
LN & 65 & $25.2 \pm 6.7$ & $15.4 \pm 3.1^{\mathrm{a}, \mathrm{b}}$ \\
LN activity groups & & & \\
LN inactive & 40 & $24.9 \pm 7.1$ & $13.4 \pm 2.7$ \\
LN active & 25 & $26.4 \pm 5.8$ & $19.2 \pm 3.9^{\mathrm{c}}$ \\
\hline
\end{tabular}

${ }^{\mathrm{a}} \mathrm{P}<0.05$ vs. healthy control; ${ }^{\mathrm{b}} \mathrm{P}<0.05$ vs. non-LN SLE; ${ }^{\mathrm{c}} \mathrm{P}<0.05$ vs. $\mathrm{LN}$ inactive. TWEAK, 1 tumor necrosis factor-related weak inducer of apoptosis; LN, lupus nephritis; SLE, systemic lupus erythematosus.

staining identified an elevated population of CD68-positive cells (Fig. 1B) and increased Ki-67 protein expression (Fig. 1C) in the LN renal tissues. As CD68 is typically used as a marker of the macrophage lineage (24), and $\mathrm{Ki}-67$ is established as a marker for cell proliferation (25), these results suggested that macrophage infiltration and cell proliferation were enhanced in the renal cortex of patients with LN.

$N F-\kappa B$ activity in $L N$ renal tissue. As the $N F-\kappa B$ signaling pathway serves an important role in cell growth and immune regulation, and the regulation of $\mathrm{NF}-\kappa \mathrm{B}$ by the TWEAK-Fn14 system has previously been indicated, the present study investigated the transcriptional activity of $\mathrm{NF}-\kappa \mathrm{B}$ in the renal tissue of patients with LN. In accordance with the results on TWEAK expression, western blotting indicated that the activation of $\mathrm{NF}-\kappa \mathrm{B}$ protein was notably elevated in the renal cortex of patients with $\mathrm{LN}$, as indicated by the elevated levels of nuclear p-p65 and p-IкB $\alpha$ (Fig. 2), which are indicators of $\mathrm{NF}-\kappa \mathrm{B}$ activation $(17,26)$.

Effect of TWEAK on $N F-\kappa B$ transcriptional activity, $H M C$ proliferation and the cell cycle. Mesangial cell proliferation is among the primary lesion characteristics of LN (27), and the immunofluorescence results suggested that cell proliferation was increased in the biopsied tissue of patients with LN (Fig. 1C). Thus, the impact of TWEAK on HMC proliferation was investigated in vivo. On flow cytometry analysis, it was observed that treatment with recombinant TWEAK significantly enhanced HMC proliferation, indicted by elevated $\mathrm{Ki}-67$ expression in the HMCs when compared with the normal (untreated) control group $(\mathrm{P}<0.05$; Fig. $3 \mathrm{~A})$. Cell cycle progression was also indicated to be promoted in the TWEAK-treated HMCs, as the ratio of cells in $\mathrm{S}+\mathrm{G} 2 / \mathrm{M}$ was significantly increased $(\mathrm{P}<0.05)$ compared with the normal control group (Fig. 3B). Additionally, compared with the normal control group, $\mathrm{I}_{\kappa} \mathrm{B} \alpha$ phosphorylation and $\mathrm{NF}-\kappa \mathrm{B}$ p65 nuclear translocation were notably increased following TWEAK treatment, which directly suggested that TWEAK enhanced NF- $\mathrm{NB}$ transcriptional activity (Fig. 3C). Following treatment with TWEAK blocking antibody, Ki-67 expression was significantly decreased $(\mathrm{P}<0.05)$, cell cycle 
A

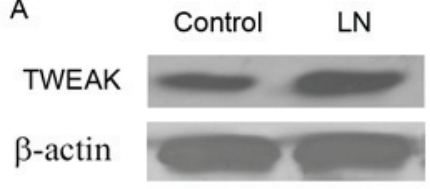

B

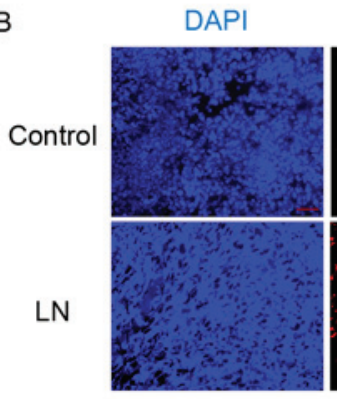

C

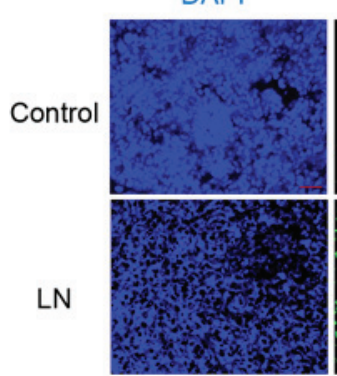

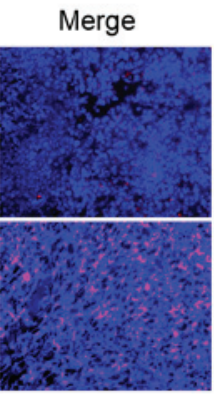
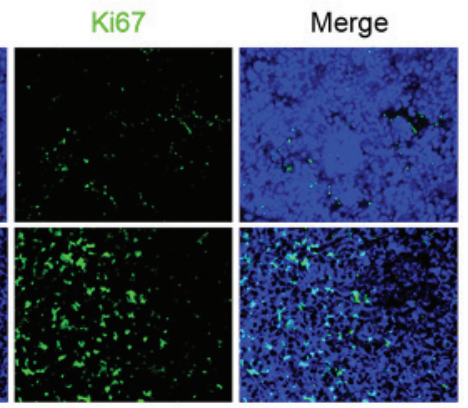

Figure 1. TWEAK expression, macrophage infiltration and Ki-67 expression in $\mathrm{LN}$ renal tissue. (A) Western blot detection of TWEAK expression in $\mathrm{LN}$ and normal control renal tissues. (B) Immunofluorescence detection of macrophage infiltration in $\mathrm{LN}$ and normal control renal tissues based on CD68 expression (red). (C) Immunofluorescence detection of Ki-67 expression (green) in LN and normal control renal tissues. Magnification, $\mathrm{x} 40$. Scale bar, $20 \mu \mathrm{m}$. TWEAK, tumor necrosis factor-related weak inducer of apoptosis; LN, lupus nephritis; DAPI, 4',6-diamidino-2-phenylindole; CD68, cluster of differentiation 68 .

Control

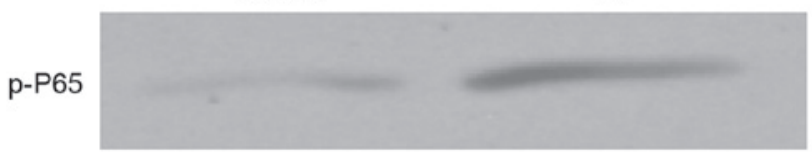

$\mathrm{p}-\mathrm{I} \kappa \mathrm{B} \alpha$

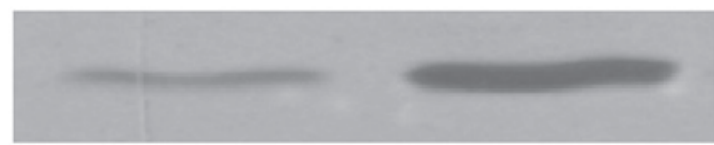

$\beta$-actin

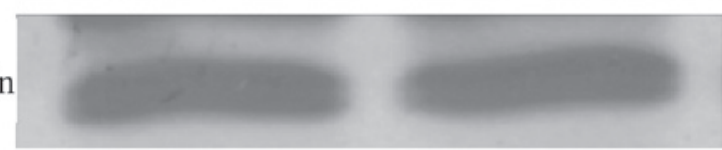

Figure 2. Nuclear factor- $\kappa \mathrm{B}$ activity is enhanced in LN renal tissue. Total protein was isolated and western blot analysis was subsequently performed

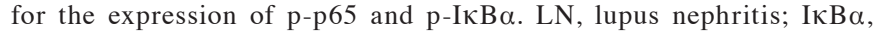
nuclear factor- $\kappa$ light polypeptide gene enhancer in B-cells inhibitor- $\alpha$; $\mathrm{p}$, phosphorylated.

progression was significantly attenuated $(\mathrm{P}<0.05)$ and $\mathrm{NF}-\kappa \mathrm{B}$ transcriptional activity was markedly reduced compared with the TWEAK positive group. Similar effects were observed following treatment with the NF- $\mathrm{B}$ specific inhibitor BAY 11-7082. Additionally, combined inhibition with BAY 11-7082 and blocking antibody significantly enhanced their inhibitory effects on cell proliferation $(\mathrm{P}<0.01)$, cell cycle progression $(\mathrm{P}<0.01)$ and to some extent, $\mathrm{NF}-\kappa \mathrm{B}$ transcriptional activity (Fig. 3A-C). These results suggested that TWEAK may elevate $\mathrm{NF}-\kappa \mathrm{B}$ transcriptional activity and promote HMC proliferation.

Effect of TWEAK on HMC cytokine secretion and macrophage migration. Macrophage infiltration in the renal tissue of patients with LN was indicated (Fig. 1B), which suggested that renal tissue may contain factors that promote macrophage migration. Therefore, the impact of HMCs on macrophage migration was investigated in vitro by Transwell assay. The results demonstrated that a limited number of macrophages migrated through the chamber membrane when co-cultured with the normal control group. Conversely, numerous macrophages migrated to the lower chamber when the chamber was occupied by TWEAK-treated HMCs; however, TWEAK blocking antibody or BAY 11-7082 treatment significantly reduced this macrophage migratory activity $(\mathrm{P}<0.05)$. Macrophage migration was further lowered on co-culture with the combined inhibition group ( $\mathrm{P}<0.01$; Fig. $4 \mathrm{~A})$.

To investigate the role of chemotactic factors in macrophage migration, RT-qPCR was performed to assess the mRNA expression of chemotactic factors in HMCs. The results demonstrated that the mRNA levels of IL-6, IL-8, MCP-1, and CCL5 were significantly increased $(\mathrm{P}<0.05)$, while IL-10 mRNA was significantly decreased $(\mathrm{P}<0.05)$ in the HMCs following TWEAK treatment (Fig. 4B). Blocking TWEAK function and/or inhibiting $\mathrm{NF}-\kappa \mathrm{B}$ activity significantly reversed these effects of TWEAK treatment $(\mathrm{P}<0.05)$, most notably in the combined inhibition group ( $\mathrm{P}<0.01$; Fig. 4B).

\section{Discussion}

In recent years, various studies have focused on the combination of SLE biomarkers and simple clinical indicators for improving the sensitivity and specificity of predictions regarding LN activity and disease progression $(28,29)$. TWEAK is a novel member of the tumor necrosis factor ligand super family that is distributed in a range of organs, including the pancreas, heart, intestine, kidney, brain, ovaries, liver, spleen, lymph nodes and skeletal muscle (30). TWEAK is also expressed in multiple cell types, including lymphocytes, macrophages, natural killer cells, renal tubular epithelial cells and glomerular mesangial cells (31). TWEAK combined with its receptor Fn14 activates the $\mathrm{NF}-\kappa \mathrm{B}$ signaling pathway to participate in inflammation, angiogenesis, cell proliferation and apoptosis (18). Multiple studies have suggested the value of TWEAK in assessing renal damage (10-12). Liu et al (32) reported that TWEAK expression in the peripheral blood mononuclear cells of patients with LN was significantly higher than that in patients with rheumatoid arthritis and healthy controls. In addition, its elevation was positively correlated with SLEDAI score, anti-double-stranded DNA content and MCP-1 expression, which suggested that TWEAK was associated with LN activity, and that abnormal chemokine levels may also participate in active LN occurrence (32). The present study identified that TWEAK content in the urine of patients with LN was significantly increased compared with that in 
A

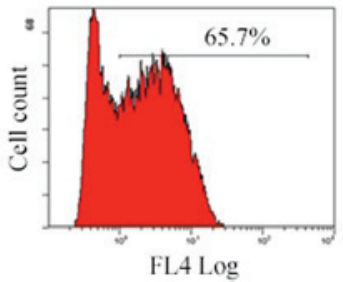

TWEAK

Blocking

Bay11-7082

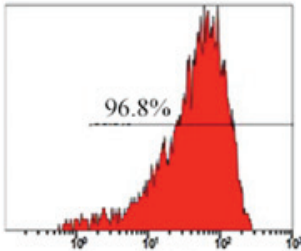

FL4 Log
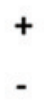

-

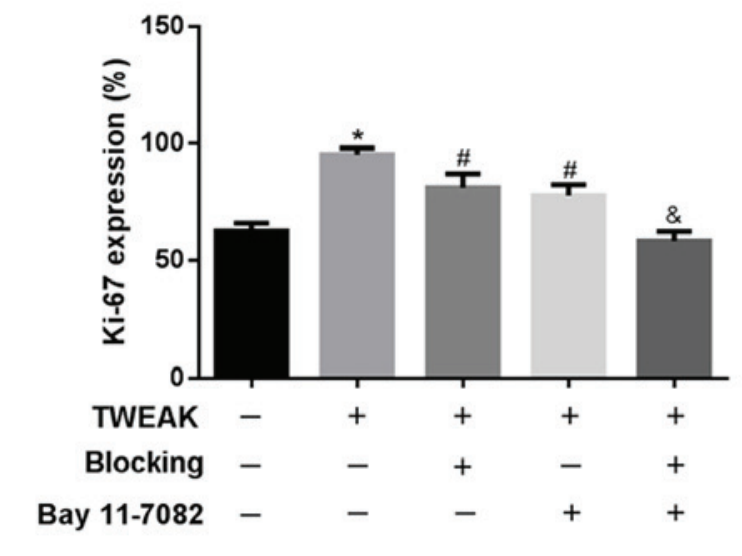

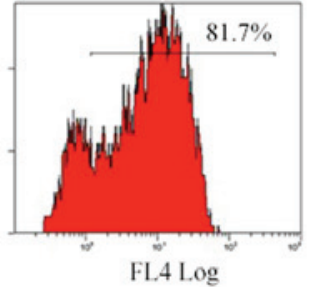

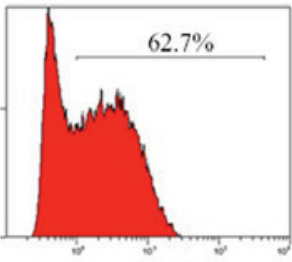

$$
\text { FLL Log }
$$
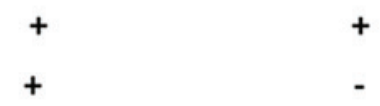

$+$

FL4 Log
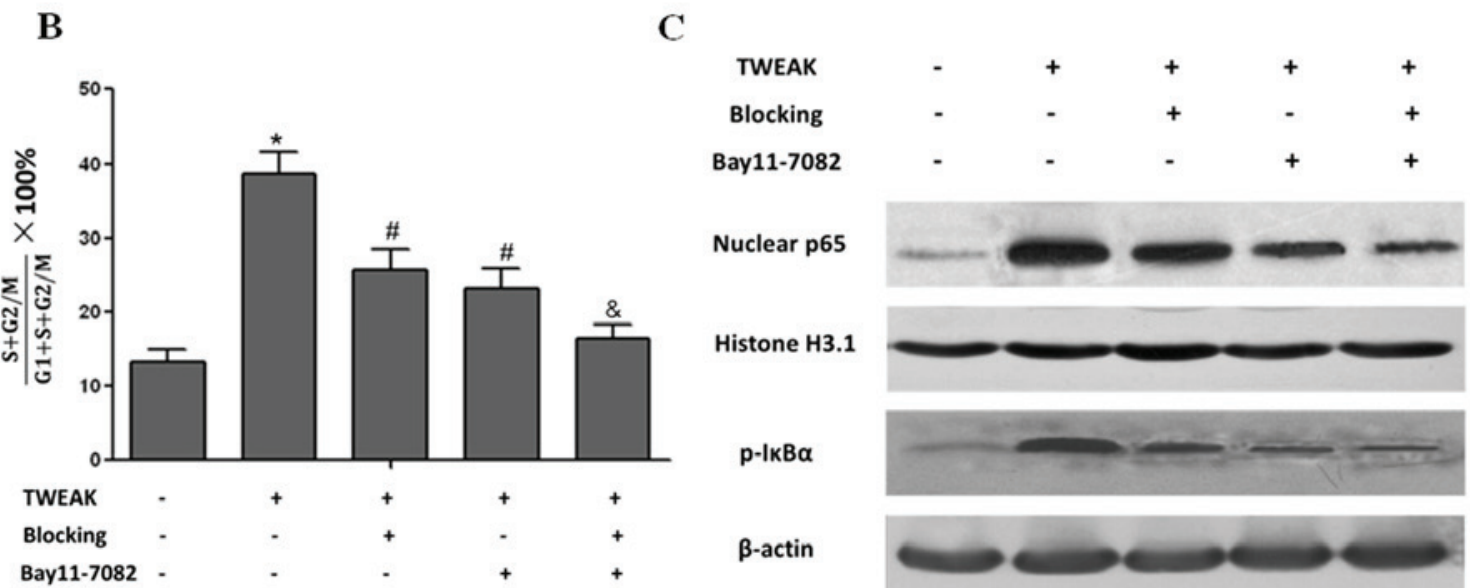

Figure 3. TWEAK elevated nuclear factor- $\kappa \mathrm{B}$ transcriptional activity and promoted human mesangial cell proliferation. (A) Flow cytometry detection of Ki-67 expression. (B) Cell cycle progression determined by flow cytometry analysis. Data are presented as the mean \pm standard deviation. (C) Western blot

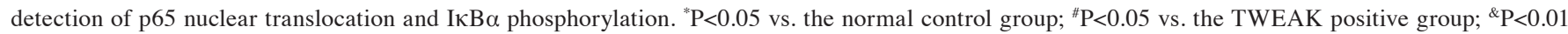

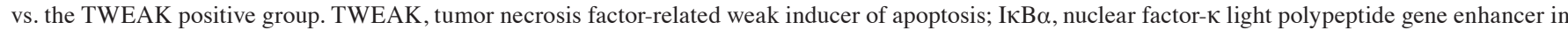
B-cells inhibitor- $\alpha$; p-, phosphorylated.

non-LN SLE patients and healthy controls. Furthermore, TWEAK levels in patients with active LN were significantly increased compared with that in patients with inactive $\mathrm{LN}$, which indicated that TWEAK may not only be associated with LN occurrence, but also with LN activity. However, the present study failed to observe a significant difference in the serum levels of TWEAK among the groups, which may be attributed to localized expression of TWEAK in LN kidney lesions, potentially resulting in its elevation in the urine via the glomerular filtration membrane (33). Western blotting results also indicated that the protein levels of TWEAK in the renal tissue of patients with $\mathrm{LN}$ were increased compared with the controls.

$\mathrm{LN}$ is a type of autoimmune disease mediated by the immune complex (34). Immune function disorder, inflammatory factor secretion and inflammatory cell infiltration are considered to be the key pathogenic factors directly involved in the pathogenesis of LN (34). In addition, dysfunction in the cytokine regulation network may cause abnormal cell proliferation and apoptosis, which has also been indicated as a notable 


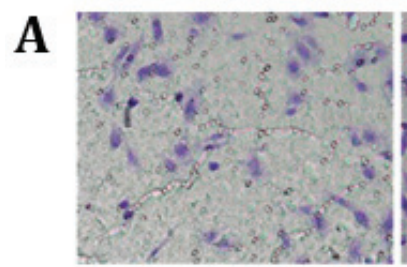

TWEAK

Blocking

Bay11-7082
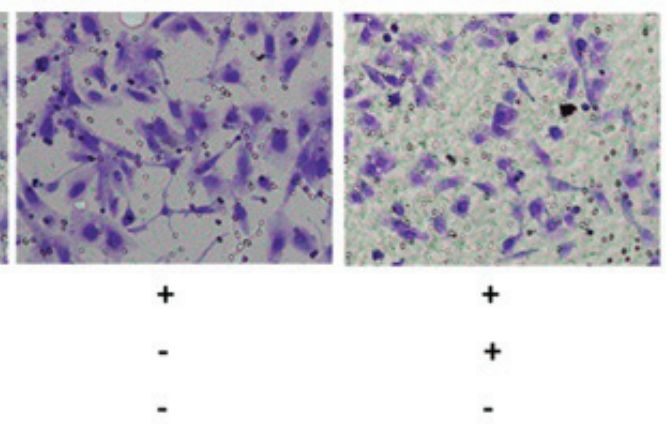

$+$

$+$

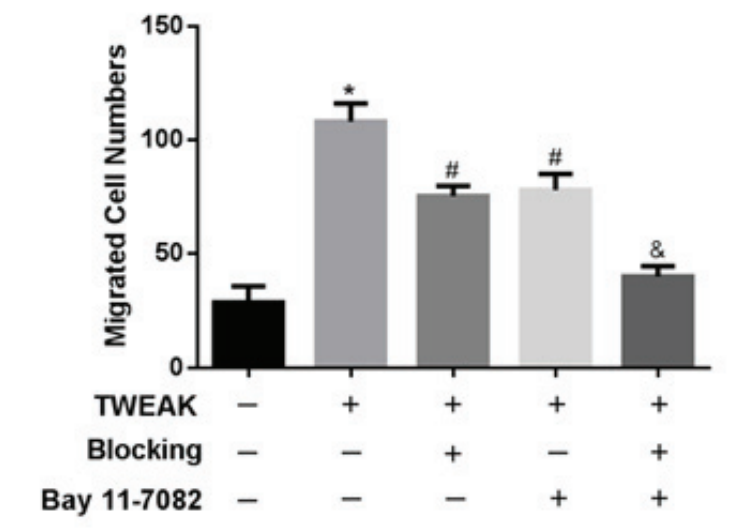

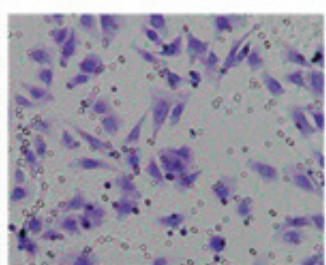

$+$
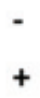
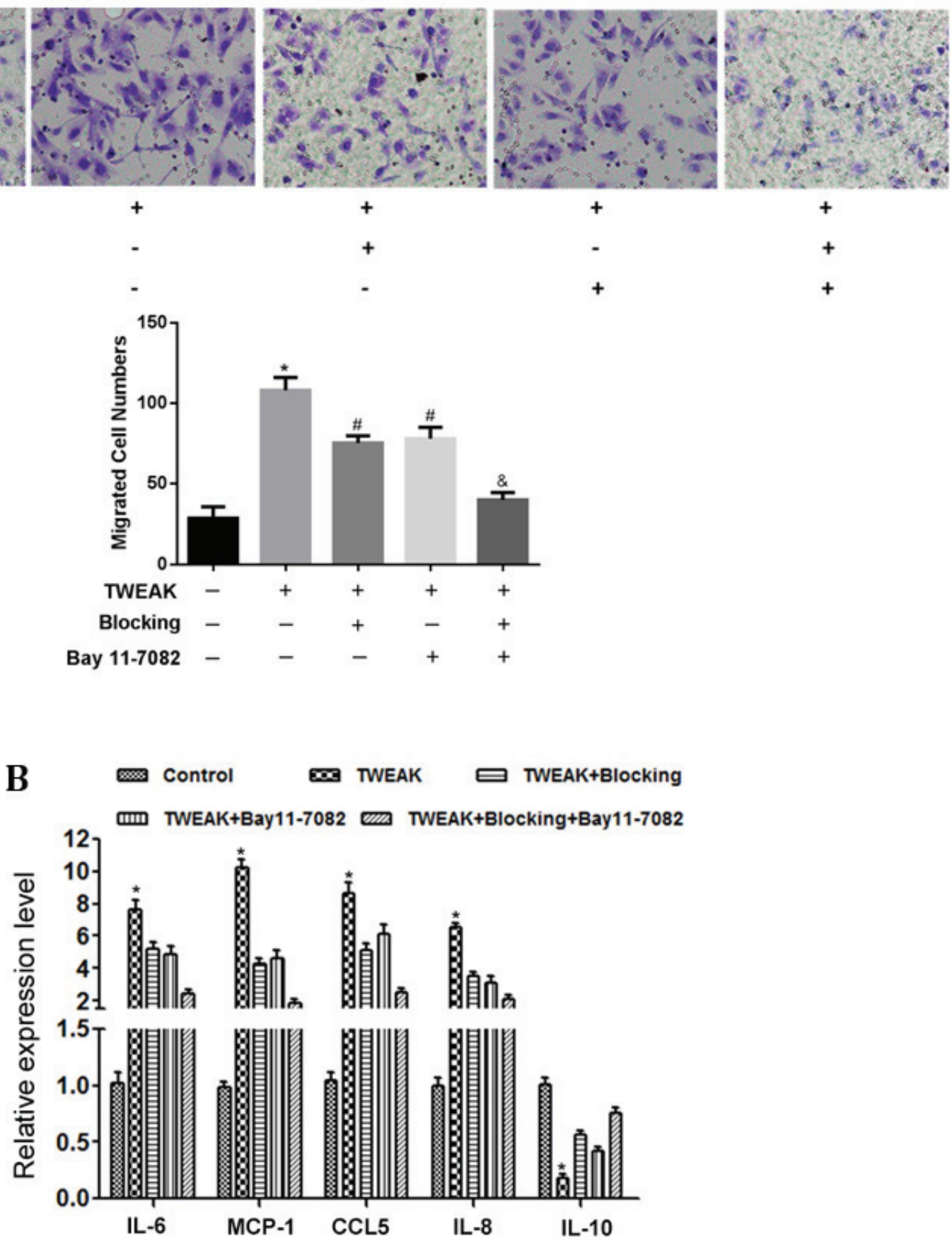

Figure 4. TWEAK affected human mesangial cell cytokine secretion and promoted macrophage migration. (A) Transwell assay detection of macrophage chemotaxis. (B) Reverse transcription-quantitative polymerase chain reaction analysis of the chemotactic factors IL-6, MCP-1, CCL5 and IL-8 and anti-inflammatory cytokine IL-10. Data are presented as the mean \pm standard deviation. ${ }^{*} \mathrm{P}<0.05$ vs. the normal control group; ${ }^{\#} \mathrm{P}<0.05$ vs. the TWEAK positive group; ${ }^{\&} \mathrm{P}<0.01$ vs. the TWEAK positive group. TWEAK, tumor necrosis factor-related weak inducer of apoptosis; IL, interleukin, MCP-1, monocyte chemotactic protein 1; CCL5, chemokine ligand 5.

factor in LN (35). For instance, abnormal cell cycle progression and hyperplasia have been confirmed to participate in LN occurrence in glomerular mesangial cells, and cell proliferation was suggested as one of the predominant pathological features of LN (36). Immunofluorescence analysis in the present study identified CD68 and $\mathrm{Ki}-67$ to be overexpressed in $\mathrm{LN}$ renal tissue compared with normal control tissue, which suggested that macrophage infiltration and cell proliferation were increased in the renal tissue of patients with LN.

$\mathrm{NF}-\mathrm{\kappa B}$ is a transcription factor that predominantly resides in the cytoplasm in the form of a p65-p50 heterodimer (17).
NF- $\mathrm{kB}$ participates in the immune inflammatory response, cell differentiation, cell growth and apoptosis regulation (17). TWEAK may activate the NF- $\mathrm{kB}$ signaling pathway through binding with Fn14, the effects of which serve to regulate cell proliferation (37), apoptosis (38), and migration (39). By comparing p65 and $\mathrm{I}_{\kappa} \mathrm{B} \alpha$ protein phosphorylation levels, the present findings indicated that $\mathrm{NF}-\mathrm{\kappa B}$ transcriptional activity was elevated in the renal tissue of patients with LN when compared with the controls, which suggested that TWEAK may be involved in the pathogenesis of LN by affecting NF- $\mathrm{KB}$ transcriptional activity. 
To investigate whether TWEAK affected cell proliferation and macrophage infiltration through $\mathrm{NF}-\kappa \mathrm{B}$, a series of in vitro experiments were performed for verification. HMCs were treated with recombinant TWEAK cytokine $(50 \mathrm{ng} / \mathrm{ml})$, and the results suggested that NF- $\mathrm{KB}$ activity was enhanced, which was consistent with the observations in pathological tissues. In addition, HMC proliferation and cell cycle progression were promoted, and macrophage chemotaxis was enhanced. In turn, blocking TWEAK cytokine and/or inhibiting NF- $\kappa \mathrm{B}$ transcriptional activity reversed these effects of TWEAK treatment, most notably with combined inhibition These results demonstrated that TWEAK may alter the biological functions of HMCs in the pathogenesis of LN by influencing $\mathrm{NF}-\kappa \mathrm{B}$ activity.

Previous research has indicated that a number of cytokines may be involved in the immune inflammatory reaction in $\mathrm{LN}$, and that imbalances between pro- and anti-inflammatory factors determine the severity and scope of the inflammatory response (35). Chemokines are a type of low molecular weight protein that promote leukocyte migration and serve an important role in the inflammatory response (40). Cytokines with critical effects on macrophage chemotaxis include MCP-1, CCL5, IL-6 and IL-8 (41). In chronic arthritis, a type of chronic inflammatory disease, it has been identified that TWEAK may induce chronic arthritis synovial cells to produce a variety of chemokines, including MMP-1, IL-6, IL-8, CCL5 and IL-10, which led to inflammatory cell migration and invasion (42). Additionally, a previous study reported that TWEAK increased MCP-1, IL-6, IL-8 and matrix metallopeptidase- 9 expression and secretion in macrophages (43). Thus, the present study investigated whether TWEAK could promote macrophage migration and invasion through HMC-expressing chemokines; the mRNA levels of chemokines in HMCs were determined to verify the influence of chemokine expression on macrophages. The results indicated that TWEAK significantly elevated the mRNA expression of IL-6, IL-8, MCP-1 and CCL5 in HMC cells, which suggested these factors may be involved in promoting TWEAK-induced macrophage migration and invasion. IL-10 is a type of anti-inflammatory factor expressed and secreted by multiple immune cells, including macrophages, T lymphocytes and B lymphocytes (44). It exerts an anti-inflammatory effect by inhibiting the expression and secretion of a variety of inflammatory factors, including interferon- $\gamma$, IL-2 and tumor necrosis factor- $\alpha$ (45). Previous results have indicated that abnormal IL-10 expression was associated with renal disease (46). Furthermore, IL-10 may prevent glomerular cell proliferation, decrease IL-1 $\beta$ and intercellular adhesion molecule- 1 expression, and alleviate inflammatory cell infiltration (47). The present results demonstrated that TWEAK reduced the mRNA level of IL-10 in HMCs, suggesting that TWEAK may promote macrophage migration by downregulating IL-10 expression.

In conclusion, TWEAK levels were increased in the renal tissue of patients with $\mathrm{LN}$, and more notably, in the urine of patients with active LN. Therefore, the urine level of TWEAK may be a novel marker of LN activity status. Additionally, the present results suggested that blocking TWEAK and the downstream NF- $\mathrm{B}$ signaling pathway may reduce $\mathrm{HMC}$ proliferation and macrophage chemotaxis, thus implicating these as novel methods and targets in the clinical treatment of LN.

\section{Acknowledgements}

The present study was supported by the Yantai Science and Technology Development Project (grant no. 2013WS237).

\section{References}

1. Manson JJ and Isenberg DA: The pathogenesis of systemic lupus erythematosus. Neth J Med 61: 343-346, 2003.

2. Mok CC and Lau CS: Pathogenesis of systemic lupus erythematosus. J Clin Pathol 56: 481-490, 2003.

3. Birmingham DJ and Hebert LA: The complement system in lupus nephritis. Semin Nephrol 35: 444-454, 2015.

4. Cross J and Jayne D: Diagnosis and treatment of kidney disease. Best Pract Res Clin Rheumatol 19: 785-798, 2005.

5. Yuste C, Gutierrez E, Sevillano AM, Rubio-Navarro A, Amaro-Villalobos JM, Ortiz A, Egido J, Praga M and Moreno JA: Pathogenesis of glomerular haematuria. World J Nephrol 4: 185-195, 2015.

6. Ortega LM, Schultz DR, Lenz O, Pardo V and Contreras GN: Review: Lupus nephritis: Pathologic features, epidemiology and a guide to therapeutic decisions. Lupus 19: 557-574, 2010.

7. Karsh J, Klippel JH, Balow JE and Decker JL: Mortality in lupus nephritis. Arthritis Rheum 22: 764-769, 1979.

8. Reyes-Thomas J, Blanco I and Putterman C: Urinary biomarkers in lupus nephritis. Clin Rev Allergy Immunol 40: 138-150, 2011.

9. Kopetschke K, Klocke J, Griessbach AS, Humrich JY, Biesen R, Dragun D, Burmester GR, Enghard P and Riemekasten G: The cellular signature of urinary immune cells in lupus nephritis: New insights into potential biomarkers. Arthritis Res Ther 17: 94, 2015.

10. Crispin JC: A TWEAK in lupus nephritis. Clin Immunol 145: 139-140, 2012.

11. Sanz AB, Izquierdo MC, Sanchez-Niño MD, Ucero AC, Egido J, Ruiz-Ortega M, Ramos AM, Putterman C and Ortiz Ap: TWEAK and the progression of renal disease: Clinical translation. Nephrol Dial Transplant 29 (Suppl 1): i54-i62, 2014.

12. Rayego-Mateos S, Morgado-Pascual JL, Sanz AB, Ramos AM, Eguchi S, Batlle D, Pato J, Keri G, Egido J, Ortiz A and Ruiz-Ortega M: TWEAK transactivation of the epidermal growth factor receptor mediates renal inflammation. J Pathol 231: 480-494, 2013.

13. Schwartz N, Su L, Burkly LC, Mackay M, Aranow C, Kollaros M, Michaelson JS, Rovin B and Putterman C: Urinary TWEAK and the activity of lupus nephritis. J Autoimmun 27: 242-250, 2006.

14. Schwartz N, Rubinstein T, Burkly LC, Collins CE, Blanco I, Su L, Hojaili B, Mackay M, Aranow C, Stohl W, et al: Urinary TWEAK as a biomarker of lupus nephritis: A multicenter cohort study. Arthritis Res Ther 11: R143, 2009.

15. Hotta K, Sho M, Yamato I, Shimada K, Harada H, Akahori T, Nakamura S, Konishi N, Yagita H, Nonomura K and Nakajima Y: Direct targeting of fibroblast growth factor-inducible 14 protein protects against renal ischemia reperfusion injury. Kidney Int 79: 179-188, 2011.

16. Zhao Z, Burkly LC, Campbell S, Schwartz N, Molano A, Choudhury A, Eisenberg RA, Michaelson JS and Putterman C: TWEAK/Fn14 interactions are instrumental in the pathogenesis of nephritis in the chronic graft-versus-host model of systemic lupus erythematosus. J Immunol 179: 7949-7958, 2007.

17. Oeckinghaus A and Ghosh S: The NF-kappaB family of transcription factors and its regulation. Cold Spring Harb Perspect Biol 1: a000034, 2009.

18. Armstrong CL, Galisteo R, Brown SA and Winkles JA: TWEAK activation of the non-canonical NF- $\kappa \mathrm{B}$ signaling pathway differentially regulates melanoma and prostate cancer cell invasion. Oncotarget 7: 81474-81492, 2016.

19. Michaelson JS, Wisniacki N, Burkly LC and Putterman C: Role of TWEAK in lupus nephritis: A bench-to-bedside review. J Autoimmun 39: 130-142, 2012.

20. Smith EL and Shmerling RH: The American College of Rheumatology criteria for the classification of systemic lupus erythematosus: Strengths, weaknesses and opportunities for improvement. Lupus 8: 586-595, 1999. 
21. Mikdashi J and Nived O: Measuring disease activity in adults with systemic lupus erythematosus: The challenges of administrative burden and responsiveness to patient concerns in clinical research. Arthritis Res Ther 17: 183, 2015.

22. Gladman DD, Ibañez D and Urowitz MB: Systemic lupus erythematosus disease activity index 2002. J Rheumatol 29: 288-291, 2000.

23. Livak KJ and Schmittgen TD: Analysis of relative gene expression data using real-time quantitative PCR and the 2(-Delta Delta C(T)) method. Methods 25: 402-408, 2001

24. Stöger JL, Gijbels MJ, van der Velden S, Manca M, van der Loos CM, Biessen EA, Daemen MJ,Lutgens E and de Winther MP Distribution of macrophage polarization markers in human atherosclerosis. Atherosclerosis 225: 461-468, 2012.

25. Sobecki M, Mrouj K, Camasses A, Parisis N, Nicolas E, Llères D, Gerbe F, Prieto S, Krasinska L, David A, et al: The cell proliferation antigen Ki-67 organises heterochromatin. Elife 5: e13722, 2016.

26. Christian F, Smith EL and Carmody RJ: The regulation of NF- $\kappa \mathrm{B}$ Subunits by phosphorylation. Cells 5: E12, 2016.

27. Wilhelmus S, Alpers CE, Cook HT, Ferrario F, Fogo AB, Haas M, Joh K, Noël LH, Seshan SV, Bruijn JA and Bajema IM: The revisited classification of GN in SLE at 10 Years: Time to re-evaluate histopathologic lesions. J Am Soc Nephrol 26 : 2938-2946, 2015.

28. Torres-Salido MT, Cortes-Hernandez J, Vidal X, Pedrosa A, Vilardell-Tarres M and Ordi-Ros J: Neutrophil gelatinase-associated lipocalin as a biomarker for lupus nephritis. Nephrol Dial Transplant 29: 1740-1749, 2014.

29. Wolf BJ, Spainhour JC, Arthur JM, Janech MG, Petri M and Oates JC: Development of biomarker models to predict outcomes in lupus nephritis. Arthritis Rheumatol 68: 1955-1963, 2016.

30. Chicheportiche Y, Bourdon PR, Xu H, Hsu YM, Scott H Hession C, Garcia I and Browning JL: TWEAK, a new secreted ligand in the tumor necrosis factor family that weakly induces apoptosis. J Biol Chem 272: 32401-32410, 1997.

31. Fragoso-Loyo H, Atisha-Fregoso Y, Nuñez-Alvarez CA and Llorente L: Utility of TWEAK to assess neuropsychiatric disease activity in systemic lupus erhytematosus. Lupus 25: 364-369, 2016

32. Liu ZC, Zhou QL, Li XZ, Yang JH, Ao X, Veeraragoo P and Zuo XX: Elevation of human tumor necrosis factor-like weak inducer of apoptosis in peripheral blood mononuclear cells is correlated with disease activity and lupus nephritis in patients with systemic lupus erythematosus. Cytokine 53: 295-300, 2011.

33. Wang C, Chen LL, Pan HF, Leng RX, Qin WZ and Ye DQ: Expression of human tumor necrosis factor-like weak inducer of apoptosis in patients with systemic lupus erythematosus. Clin Rheumatol 31: 335-339, 2012.
34. Lech M and Anders HJ: The pathogenesis of lupus nephritis J Am Soc Nephrol 24: 1357-1366, 2013.

35. Iwata Y, Furuichi K, Kaneko S and Wada T: The role of cytokine in the lupus nephritis. J Biomed Biotechnol 2011: 594809, 2011.

36. Feng X, Hao J, Liu Q, Yang L, Lv X, Zhang Y, Xing L, Xu N and Liu S: HMGB1 mediates IFN- $\gamma$-induced cell proliferation in MMC cells through regulation of cyclin D1/CDK4/p16 pathway. J Cell Biochem 113: 2009-2019, 2012.

37. Chen HN, Wang DJ, Ren MY, Wang QL and Sui SJ: TWEAK/Fn14 promotes the proliferation and collagen synthesis of rat cardiac fibroblasts via the NF- $\kappa$ B pathway. Mol Biol Rep 39: 8231-8241, 2012.

38. Kwon OH, Kim JH, Kim SY and Kim YS: TWEAK/Fn14 signaling mediates gastric cancer cell resistance to 5-fluorouracil via NF-кB activation. Int J Oncol 44: 583-590, 2014.

39. Cherry EM, Lee DW, Jung JU and Sitcheran R: Tumor necrosis factor-like weak inducer of apoptosis (TWEAK) promotes glioma cell invasion through induction of NF-kappaB-inducing kinase (NIK) and noncanonical NF- $\mathrm{BB}$ signaling. Mol Cancer 14: $9,2015$.

40. Cameron MJ and Kelvin DJ: Cytokines and chemokines-their receptors and their genes: An overview. Adv Exp Med Biol 520: 8-32, 2003.

41. Turner MD, Nedjai B, Hurst T and Pennington DJ: Cytokines and chemokines: At the crossroads of cell signalling and inflammatory disease. Biochim Biophys Acta 1843: 2563-2582, 2014.

42. Chicheportiche Y, Chicheportiche R, Sizing I, Thompson J, Benjamin CB, Ambrose C and Dayer JM: Proinflammatory activity of TWEAK on human dermal fibroblasts and synoviocytes: Blocking and enhancing effects of anti-TWEAK monoclonal antibodies. Arthritis Res 4: 126-133, 2002.

43. Kim SH, Kang YJ, Kim WJ, Woo DK, Lee Y, Kim DI, Park YB, Kwon BS, Park JE and Lee WH: TWEAK can induce pro-inflammatory cytokines and matrix metalloproteinase-9 in macrophages. Circ J 68: 396-399, 2004.

44. Moore KW, de Waal Malefyt R, Coffman RL and O'Garra A: Interleukin-10 and the interleukin-10 receptor. Annu Rev Immunol 19: 683-765, 2001.

45. Iyer SS and Cheng G: Role of interleukin 10 transcriptional regulation in inflammation and autoimmune disease. Crit Rev Immunol 32: 23-63, 2012

46. Sinuani I, Beberashvili I, Averbukh Z and Sandbank J: Role of IL-10 in the progression of kidney disease. World J Transplant 3 : 91-98, 2013

47. Kitching AR, Katerelos M, Mudge SJ, Tipping PG, Power DA and Holdsworth SR: Interleukin-10 inhibits experimental mesangial proliferative glomerulonephritis. Clin Exp Immunol 128: 36-43, 2002. 